\title{
Synthesis, structure and electromagnetic properties of FeCoAl/C nanocomposites
}

\author{
Dmitriy G. Muratov 1,2, Lev V. Kozhitov², Egor V. Yakushko², Andrey A. Vasilev,2, \\ Alena V. Popkova ${ }^{3}$, Vitaly A. Tarala ${ }^{4}$, Evgeniy Yu. Korovin ${ }^{5,6}$ \\ 1 A.V. Topchiev Institute of Petrochemical Synthesis, Russian Academy of Sciences, 29 Leninsky Ave., Moscow 119991, Russia \\ 2 National University of Science and Technology MISiS, 4 Leninsky Ave., Moscow 119049, Russia \\ 3 JSC "Research Institute NPO” LUCH”, 24 Zheleznodorozhnaya Str., Podolsk, 142103, Russia \\ 4 North Caucasus Federal University, 1 Pushkin Str., Stavropol 355017, Russia \\ 5 Institute of Physical Materials Science, Siberian Branch of the Russian Academy of Sciences, 6 Sakhyanova Str., Ulan-Ude 670047, \\ Republic of Buryatia, Russia \\ 6 Tomsk State University, 36 Lenin Ave., Tomsk 634050, Russia
}

Corresponding author: Lev V. Kozhitov (kozitov@misis.ru)

Received 26 August 2021 Accepted 10 September 2021 Published 30 September 2021

Citation: Muratov DG, Kozhitov LV, Yakushko EV, Vasilev AA, Popkova AV, Tarala VA, Korovin EYu (2021) Synthesis, structure and electromagnetic properties of FeCoAl/C nanocomposites. Modern Electronic Materials 7(3): 99-108. https://doi.org/10.3897/j. moem.7.3.77105

\begin{abstract}
Magnetic nanoparticles play an important role in rapidly developing advanced branches of science and industry, e.g. fabrication of magnetic storage media, synthesis of ferromagnetic liquids, medicine and chemistry. One problem faced in the usage of magnetic nanoparticles is their high chemical activity leading to oxidation in air and agglomeration. The chemical activity of magnetic nanoparticles stems from the contribution of their large specific surface to volume ratio. Carbon coating of nanoparticles reduces the interaction between nanoparticles. FeCoAl/C metal-carbon nanocomposites have been synthesized using IR pyrolysis of polymer/metal salt precursors. The effect of synthesis temperature (IR heating) in the range from 500 to $700{ }^{\circ} \mathrm{C}$ on the structure and composition of the nanomaterials has been studied. We show that the forming particles are the FeCoAl ternary solid solution with a FeCo based bcc lattice. An increase in the synthesis temperature from 500 to $700{ }^{\circ} \mathrm{C}$ leads to an increase in the coherent scattering region of three-component nanoparticles from 5 to $19 \mathrm{~nm}$. An increase in the aluminum content from 20 to $30 \%$ relative to $\mathrm{Fe}$ and Co results in an increase in the size of the nanoparticles to $15 \mathrm{~nm}$ but this also entails the formation of a Co based solid solution having an fcc lattice. An increase in the nanocomposite synthesis temperature and a growth of the relative $\mathrm{Al}$ content as a result of a more complete carbonization and the structure-building effect of metals reduce the degree of amorphousness of the nanocomposite carbon matrix and lead to the formation of graphite-like phase crystallites having an ordered structure. The effect of synthesis temperature and relative content of metals on the electromagnetic properties (complex permittivity and permeability) of the synthesized nanocomposites has been studied. Synthesis conditions affect the radio absorption properties of the nanocomposites, e.g. reflection loss (RL) in the 3-13 GHz range.
\end{abstract}

\section{Keywords}

FeCoAl nanoparticles, carbon matrix, metal-carbon nanocomposites, IR pyrolysis, X-ray phase analysis, Raman spectroscopy, complex permittivity, complex permeability, reflection loss. 


\section{Introduction}

Magnetic nanoparticles play an important role in rapidly developing advanced branches of science and industry. The use of magnetic nanoparticles shows good promise primarily for the following fields:

- development of magnetic storage media and ferromagnetic liquids $[1,2]$;

- medicine (transport of medication, contrast agent for magnetic resonance tomography, hyperthermal treatment [3]);

- chemistry (catalysts in petrochemical processes [4]).

The unique physical and chemical properties of iron group metal based alloys originate from their structural properties, electron structure and chemical composition [5-11].

One problem faced in the usage of magnetic nanoparticles is their high chemical activity leading to oxidation in air and agglomeration. The chemical activity of magnetic nanoparticles stems from the contribution of their large specific surface to volume ratio. Carbon coating of nanoparticles reduces the interaction between the nanoparticles but it should be borne in mind that the low degree of crystallinity and graphite shell defects deleteriously affect the protective properties of the coating $[12,13]$.

Synthesized nanoparticles of iron group metals and alloys without protective coatings are oxidized in air to form oxide films that lead to a significant loss in the ferromagnetic properties. Along with protection, graphite coatings tangibly improve the absorption of electromagnetic waves by metal and alloy nanoparticles. There are two mechanisms underlying this effect: dielectric loss and magnetic loss, with the proper ferromagnetic resonance often occurring at a higher frequency in comparison with that for bulk materials [14].

Another factor allowing one to control the properties of the nanocomposites is the interaction between magnetic particles and the matrix where the magnitude of dipole interaction depends considerably on the textural parameters of the matrix in which the nanomagnetic particles are dispersed [15].

During the synthesis of nanocomposites the ferromagnetic alloy particles, e.g. FeCo, are protected by shells of a nonmagnetic chemically stable material, i.e., carbon, and are synthesized with different morphologies such as nanocoatings [16-19], nanochips [20], nanotubes [21, $22]$ and nanofibers $[23,24]$ with the aim to increase the radio absorption properties of the particles. The main advantage of the use of nanostructurized hybrid materials is an increase in the relative complex permeability and dielectric permeability. The mechanisms that increase the complex permeability including the suppression of eddy currents reduce the back reflection and increase the crystallographic magnetic anisotropy which affects the resonance frequency. Different mechanisms such as polarization between the magnetic and dielectric phases and the natural electron relaxation of the dielectric phase also increase the complex permittivity [16-26].

Methods of synthesizing the carbon shells of magnetic nanoparticles include arc discharge [19], hydrothermal treatment [27], magnetron and ion beam sputtering [28], laser pyrolysis of organic compounds [29] and sputtering techniques [30], The use of carbon as an oxidation protecting shell for magnetic materials has been reported earlier [17-21, 24, 31].

Many of these methods have drawbacks such as incomplete carbon coverage of nanoparticle surface, low graphite formation efficiency and difficult control of carbon coating homogeneity as well as the necessity of an additional heat treatment stage for carbon particle oxidation protection. Therefore an important task is the development of new magnetic material nanoparticle synthesis techniques which can deliver nanoparticles and an oxidation protecting matrix in a single process without the use of a reducing agent.

We developed a method of synthesizing metal/carbon nanocomposites with the use of a system that includes metal salts, a polymer and a solvent by IR heating pyrolysis which is a new and promising trend in the development of new efficient radio absorbing coatings and materials $[32,33]$. An important advantage of this method is the possibility of the simultaneous production of multicomponent nanoparticles of $\mathrm{FeCoMe}(\mathrm{Ni}, \mathrm{Sm}, \mathrm{Cr}, \mathrm{Cu}, \mathrm{Al})$ alloys and a carbon matrix through polymer carbonization. In fact the carbon matrix represents an implementation of the model of a FeCoMe core and a pyrolyzed polymer shell. Cobalt and nickel are quite expensive metals and it is therefore expedient to partially replace them for other metals e.g. Al in multicomponent alloys.

Being aware of $\mathrm{FeCoAl} / \mathrm{C}$ nanocomposite formation process specific features one can control the magnetic and electromagnetic properties of the materials by varying the elemental composition, structure, morphology and crystalline structure of the multicomponent nanoparticles. Furthermore we gain the possibility of controlling the structure of the carbon matrix which binds the alloy nanoparticles but avoids their agglomeration, oxidation and direct magnetic exchange interaction while retaining a high proportion of the surface.

The importance of this work is dictated by the absence of current literary data on any $\mathrm{FeCoAl} / \mathrm{C}$ nanocomposite technology.

\section{Experimental}

$\mathrm{FeCoAl} / \mathrm{C}$ nanocomposites were synthesized from a precursor consisting of polyacrylonitrile, metal salts and a solvent. Polyacrylonitrile had a molecular weight of 100 250 ths. at. units (powder) produced by oxidation-reduction polymerization. The metal source was iron acetyl acetonate $\mathrm{Fe}\left(\mathrm{CH}_{3} \mathrm{COCH}=\mathrm{C}\left(\mathrm{CH}_{3}\right) \mathrm{O}\right)_{3}$, 4-aqueous cobalt acetate $\left(\mathrm{Co}\left(\mathrm{CH}_{3} \mathrm{COO}\right)_{2} \cdot 4 \mathrm{H}_{2} \mathrm{O}\right)$ and non-aqueous aluminum chloride $\left(\mathrm{AlCl}_{3}\right)$. 
For achieving a homogeneous initial distribution of the metals in the polymer we made a solution of polyacrylonitrile with metal salts in a common solvent, i.e., dimethylformamide.

After solution drying at $70{ }^{\circ} \mathrm{C}$ to a solid residue with a constant weight (hereiunefter the precursor) the specimens were subjected to two-stage IR pyrolysis:

- first stage (preliminary air anneal): stepwise heating to $150{ }^{\circ} \mathrm{C}$ with $15 \mathrm{~min}$. holding followed by heating to $220^{\circ} \mathrm{C}$ with $15 \mathrm{~min}$. tempering (ion air);

- second stage: further vacuum pyrolysis $(\sim 200 \mathrm{~Pa})$ at 500 to $700{ }^{\circ} \mathrm{C}$ followed by $10 \mathrm{~min}$. tempering, the heating rate being $50 \mathrm{~K} / \mathrm{min}$.

$\mathrm{X}$-ray diffraction and phase analyses were conducted at room temperature on a DIFRAY instrument in $\mathrm{Cr}_{K \alpha}$ radiation. The experimental results were compared with PDF-4 standards (International Centre for Diffraction Data, ICDD). Based on X-ray diffraction phase analysis data we calculated the average size of the synthesized FeCo alloy nanoparticles using the Debye-Scherrer equations.
Raman spectra were taken on an inVia Raman Microscope spectrometer (Renishaw plc) with $514 \mathrm{~nm}$ laser wave excitation.

The complex magnetic and dielectric permeabilities were measured by a resonance method on a rectangular multimode resonator. The HF generator and indicator was a E 8363 B vector network analyzer from Agilent Technologies. The measurements were conducted using instruments and methods developed by the Joint Use Center for Radiological Measurements, Diagnostics and Parametric Research of Natural and Artificial Materials of the Tomsk State University (http://www.ckp.tsu.ru/ about/directions/radiophysics).

\section{Results and discussion}

IR synthesis of polyacrylonitrile and the formation of its carbon matrix involve emission of a significant amount of gaseous products including $\mathrm{H}_{2}, \mathrm{NH}_{3}$ and $\mathrm{CO}$ which act as reducers for metallic compounds. It should be borne in
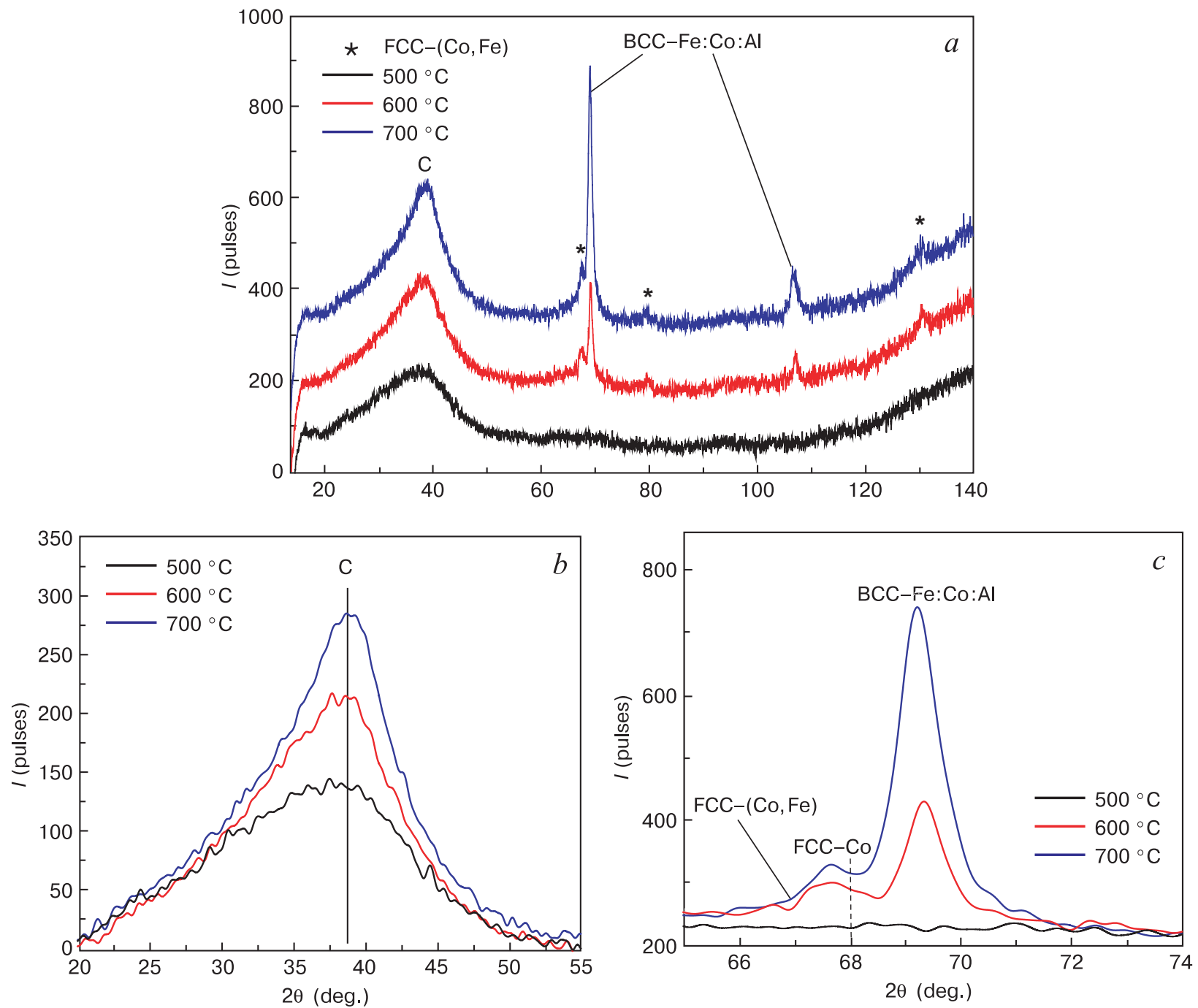

Figure 1. (a) X-ray diffraction patterns of $\mathrm{FeCoAl} / \mathrm{C}$ nanocomposites synthesized at different temperatures, $(b)$ fragments of $\mathrm{X}$-ray patterns in the vicinity of the angular range for the graphite (002) plane and (c) for the (111) and (110) planes of the metallic alloy. 

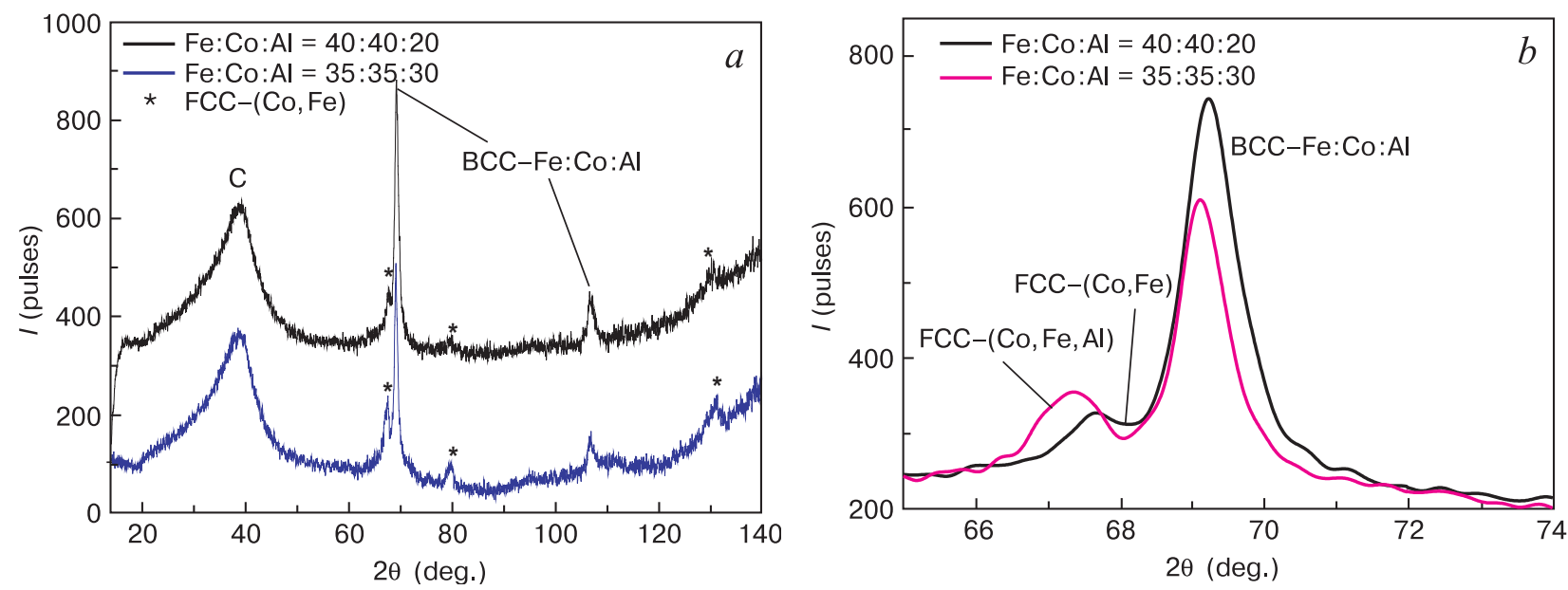

Figure 2. (a) X-ray diffraction patterns of nanocomposites and (b) fragment of X-ray diffraction pattern near $2 \theta=65^{\circ} \div 74^{\circ}$ for different ration of metal weights $\mathrm{Fe}: \mathrm{Co}: \mathrm{Al}\left(T_{\text {synth }}=700^{\circ} \mathrm{C}\right)$.

mind that reduction occurs in the solid state and therefore metal reduction is an in situ process which may involve atomic hydrogen which forms due to destruction of the main polymer chain during IR heating.

Introduction of a non-magnetic modifying metal (Al) which is often used for the synthesis of various iron based magnetic alloys into the $\mathrm{Fe}-\mathrm{Co}$ system changes the microstructure and properties of the alloys.

$\mathrm{X}$-ray phase analysis showed that, unlike $\mathrm{FeCo} / \mathrm{C}$ nanocomponents with an equiatomic content of metals, the formation of a single-phase system does not occur in polyacrylonitrile based $\mathrm{FeCoAl} / \mathrm{C}$ nanocomposites. $\mathrm{X}$-ray patterns of $\mathrm{FeCoAl} / \mathrm{C}$ nanocomposites synthesized in the 500 to $700{ }^{\circ} \mathrm{C}$ range are shown in Fig. 1 .

$\mathrm{X}$-ray phase analysis shows that metals or oxides in nanocomposites synthesized at $T=500{ }^{\circ} \mathrm{C}$ are in an $\mathrm{X}$-ray amorphous state (the average particle size is within 3-5 nm). Two metallic phases having bec and fcc lattices precipitate at a higher synthesis temperature $\left(600{ }^{\circ} \mathrm{C}\right)$. The good solubility of $\mathrm{Al}$ in Fe suggests that bcc FeCo alloy lattice based $\mathrm{FeCoAl}$ solid solution particles (19 nm at $700{ }^{\circ} \mathrm{C}$ ) form whereas the fcc phase is represented by nanoparticles consisting of an iron solid solution in cobalt.

Increasing the synthesis temperature to $700{ }^{\circ} \mathrm{C}$ does not change the phase composition of the nanocomposite.

According to the X-ray phase analysis data, bcc lattice FeCoAl nanoparticles co-exist with fcc lattice ones. The X-ray peak of the fcc phase shifts slightly probably due to the dissolution of a small fraction of aluminum in the $(\mathrm{Co}, \mathrm{Fe})$ solid solution. The formation of this solid solution is entailed by the presence of iron and cobalt in which aluminum solubilities differ.

It should be noted that the fcc phase peaks are shifted towards lower angles relative to the pure cobalt ones $\left(2 \theta=68,02^{\circ} ; 80,48^{\circ} ; 132^{\circ}\right.$ (ID: 150806$\left.)\right)$ suggesting the substitution dissolution of a large quantity of iron and aluminum in cobalt. No aluminum oxides were found; this suggests their X-ray amorphousness or dissolution in other metals with the formation of alloys. The formation of an alloy is further confirmed by the shift of the bcc phase peaks towards lower angles suggesting the dissolution of $\mathrm{Al}$ since $\mathrm{Al}$ has a larger radius $(0.143 \mathrm{~nm}$ for $\mathrm{Al}$ and 0.126 for iron).

The change in the nanocomposite composition towards an increase in the fraction of aluminum from 20 to $30 \mathrm{rel} . \%$ does not lead to any noticeable change in the phase composition of the material but changes the intensity of the peaks of the metallic phases and slightly shifts the peaks relative to the composition $\mathrm{Fe}: \mathrm{Co}: \mathrm{Al}=$ $40: 40: 20$ (Fig. 2).

Since the radius of the $\mathrm{Al}$ atom is greater than that of iron and cobalt the dissolution of aluminum leads to a greater shift of the solid solution fcc phase peaks.

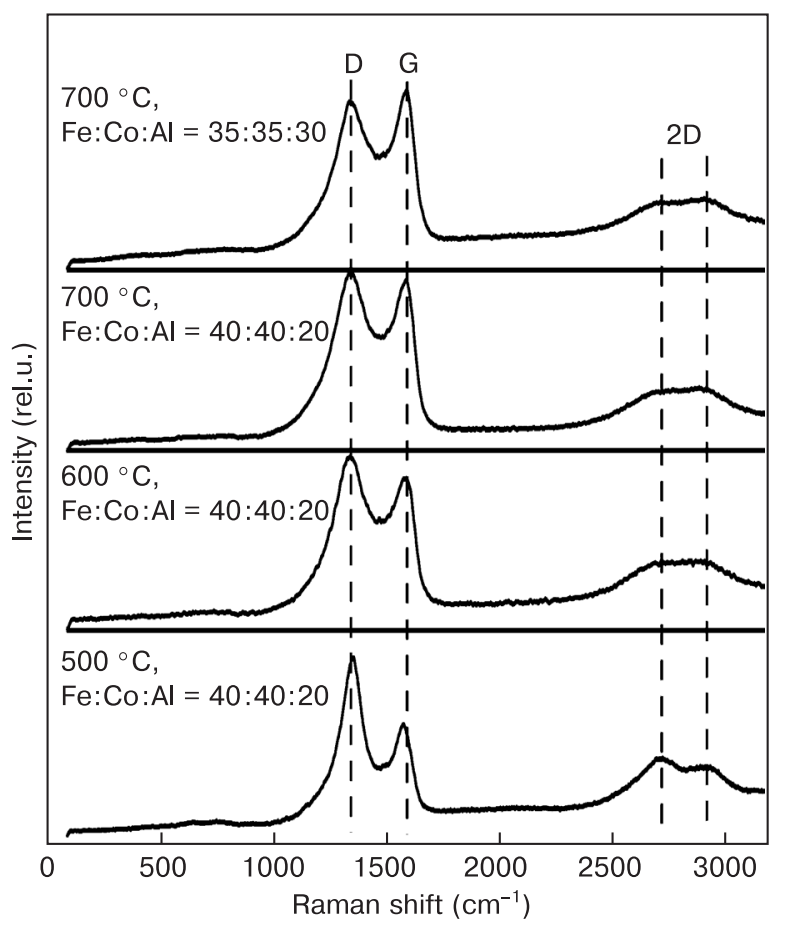

Figure 3. Raman spectra of $\mathrm{FeCoAl} / \mathrm{C}$ nanocomposites synthesized at different temperatures and metal ratios. 
Furthermore the bcc phase peaks shift towards lower angles and this is another indication of aluminum dissolution.

Estimation of the coherent scattering region yielded $10 \mathrm{~nm}$ for the fcc phase of the ternary alloy and $15 \mathrm{~nm}$ for the bcc phase.

Thus an increase in the fraction of aluminum reduces the average nanoparticle size by $4 \mathrm{~nm}$ for the bcc phase and increases the nanoparticle size for the fcc phase.

Heat treatment of polyacrylonitrile triggers a number of chemical reactions, and carbonization produces a carbon material that can be considered as a nanocrystalline one [34]. It was reported that, in the presence of metals, complex carbon structures [35-38] may form which can have a substantial effect on the properties of the nanocomposites obtained.
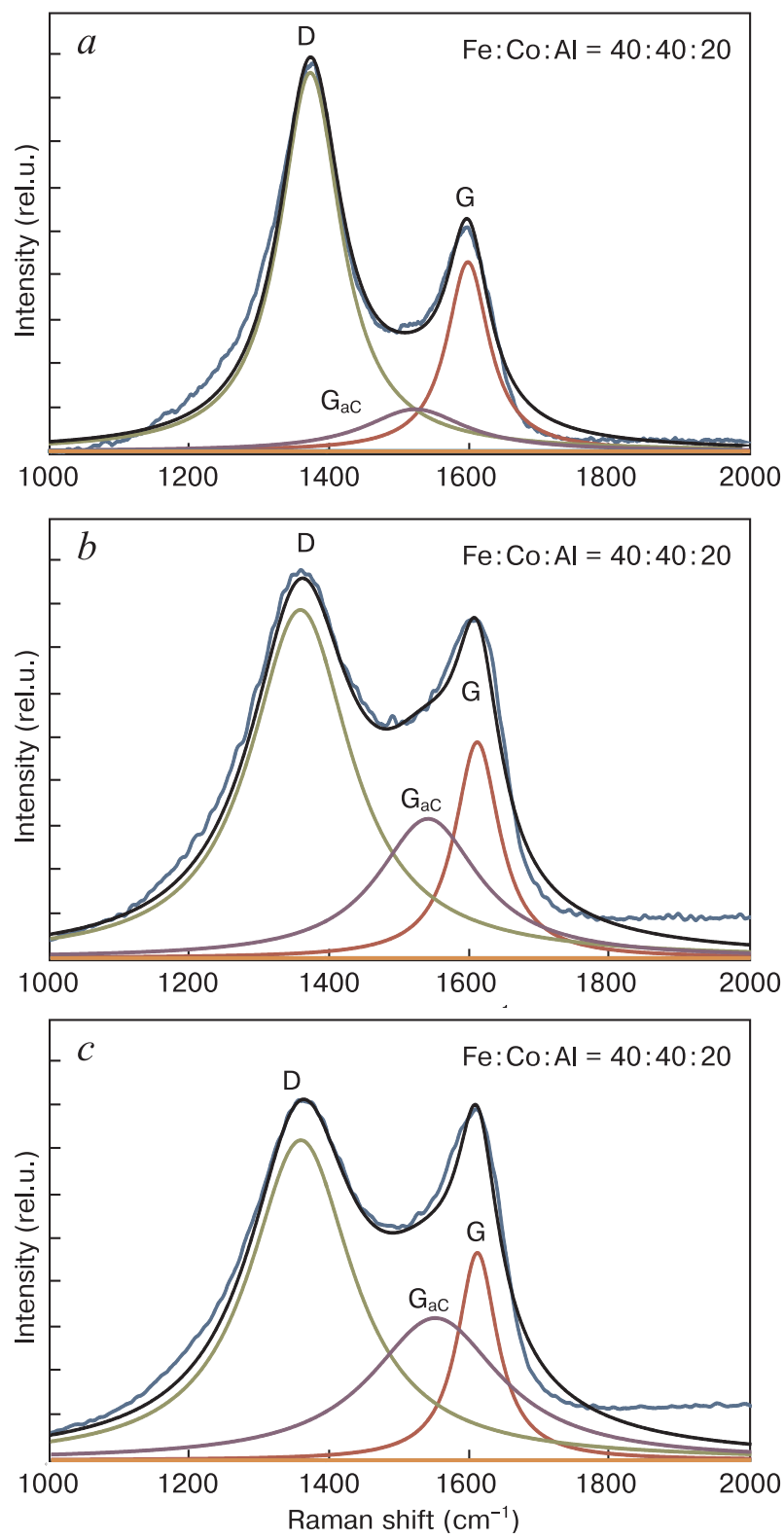

Figure 4. Deconvolution of Raman spectra of $\mathrm{FeCoAl} / \mathrm{C}$ nanocomposites sytnthesized at different temperatures $\left({ }^{\circ} \mathrm{C}\right):(a) 500$; (b) $600 ;(c) 700$.
The Raman spectra of $\mathrm{FeCoAl} / \mathrm{C}$ metal-carbon composites shown in Fig. 3 demonstrate that with an increase in synthesis temperature the ratio between the $\mathrm{D}$ band intensity $\left(I_{\mathrm{D}}\right)$ and the $\mathrm{G}$ band intensity $\left(I_{\mathrm{G}}\right)$ decreases. Furthermore a slight decrease in $\left(I_{\mathrm{D}} / I_{\mathrm{G}}\right)$ was observed with an increase in the fraction of $\mathrm{Al}$ in the nanocomposites (the Fe : Co : Al ratio was changed from $40: 40: 20$ to $35: 35: 30$ ).

Earlier data [39] demonstrate that a change in the $\left(I_{\mathrm{D}} / I_{\mathrm{G}}\right)$ ratio indicates a change in the size of the carbon clusters $\left(L_{\mathrm{a}}\right)$ consisting of hexagonal aromatic rings.

The size of these clusters can be estimated using the following equation [40]:

$$
I_{\mathrm{D}} / I_{\mathrm{G}}=C(\lambda) / L_{\mathrm{a}}
$$

where $C(\lambda)$ is a coefficient depending on laser wavelength: for laser with $\lambda=5.4 \mathrm{~nm} C(\lambda)=4.4 \mathrm{~nm}$, This estimate showed that $L_{\mathrm{a}}$ with an increase in the synthesis temperature from 500 to $700{ }^{\circ} \mathrm{C}$ increases from $25-30$ to $40 \mathrm{~nm}$.

In order to study in detail the changes in the microstructure of the carbon matrix as a result of an increase in the synthesis temperature we deconvoluted the Raman spectra into three bands $\mathrm{D}, \mathrm{G}$ and $\mathrm{G}_{\mathrm{aC}}$, where the band $\mathrm{G}_{\mathrm{aC}}$ peaking at $1520-1540 \mathrm{~cm}^{-1}$ is the contribution of amorphous carbon clusters.

It can be seen from Fig. 4 that the greatest structural transformations in the test materials occur at 500 to $600^{\circ} \mathrm{C}$. In accordance with earlier data [41] the trend of decreasing the $I_{\mathrm{D}} / I_{\mathrm{GaC}}$ ratio indicates a decrease in the size of amorphous carbon clusters.

Each band was described using the Lorentz distribution.

The results showed that with an increase in the synthesis temperature of $\mathrm{FeCoAl} / \mathrm{C}$ nanocomposites the sizes of the crystalline clusters in the microstructure of the carbon matrix decrease, i.e., the amorphousness degree of the material decreases.

The structural transformations in the nanocomposite matrix and the changes in the size and composition of nanoparticles with an increase in the synthesis temperature entail tangible changes in the electromagnetic properties of the materials.

Data on the effect of synthesis temperature on the dielectric and magnetic properties of the nanocomposites in HF fields are shown in Fig. 5.

The data shown in Fig. $5 b$ suggest that the $\mu$ " component of the complex permeability increases significantly with an increase in the synthesis temperature. Taking into account that this component describes the fraction of absorbed radiation, an increase in this parameter from 0.04 to 0.12 leads to an increase in the magnetic loss. The curve has a peak at $\sim 11 \mathrm{GHz}$ which seems to originate from an increase in $\mathrm{FeCoAl}$ alloy nanoparticle sizes and hence an increase in the magnetization of the nanocomposite. The real part of the complex magnetic permeability also increases by approx. $10 \%$ with an increase in the 

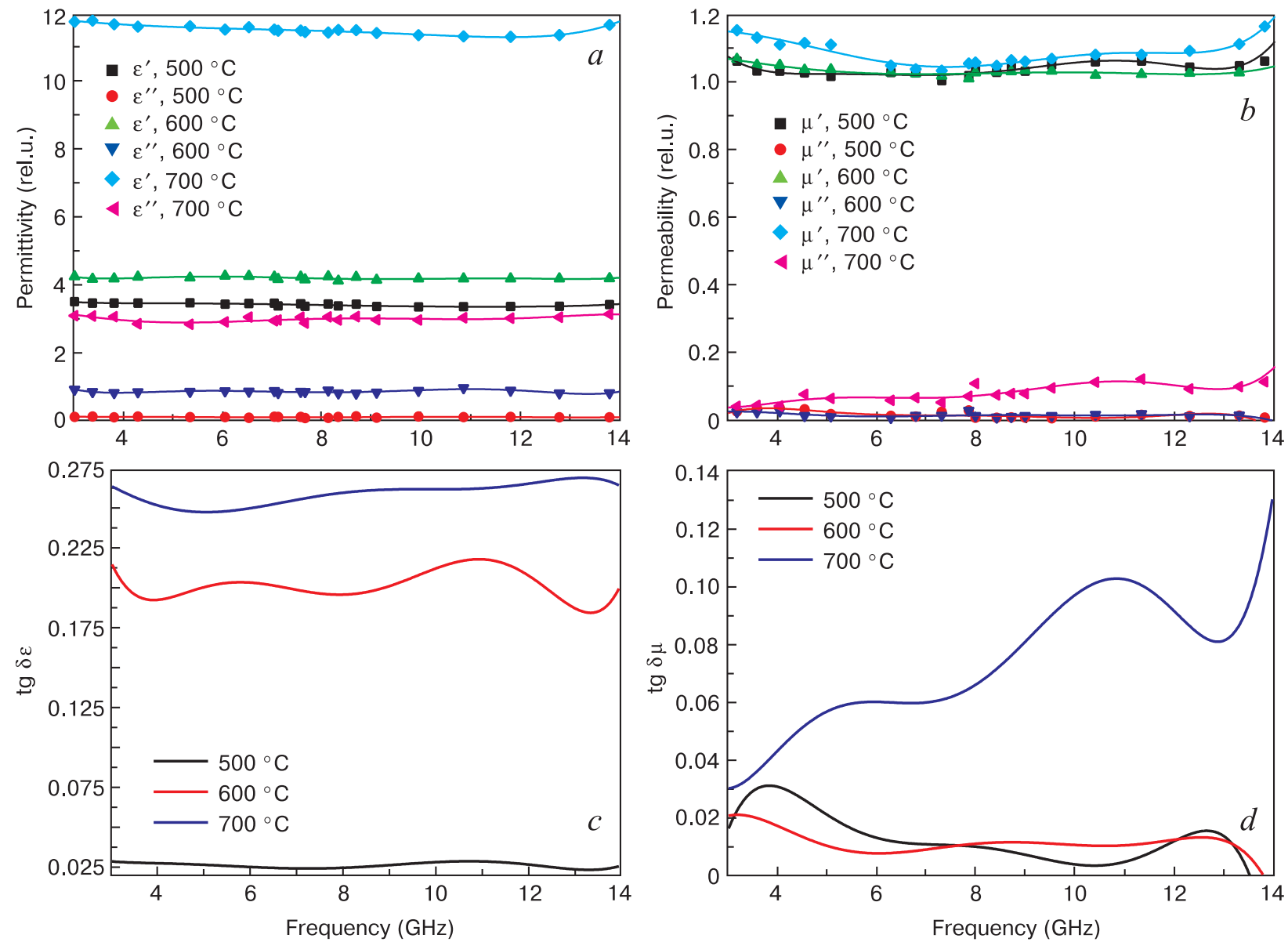

Figure 5. Frequency dependences of $(a)$ complex permittivity and $(b)$ permeability and tangents of $(c)$ dielectric and $(d)$ magnetic loss for different $\mathrm{FeCoAl} / \mathrm{C}$ nanocomposite synthesis temperatures.

nanocomposite synthesis temperature. Coupled with the changes in the imaginary part of the complex magnetic permeability this causes an increase in the magnetic loss tangent in the test frequency range.

The dielectric permeability and the magnetic dielectric loss tangent (Fig. $5 a$ and $c$ ) also increase with the synthesis temperature. The growth is the greatest in the 500 to $600{ }^{\circ} \mathrm{C}$ range which is in agreement with the $\mathrm{X}$-ray phase analysis data and the conclusions from the Raman study.

From the practical application viewpoint the fabrication of radio absorbing components of structures on the basis of the nanocomposites synthesized in this work having the smallest weight and dimensions is the most efficient for the frequencies of natural ferromagnetic resonance since the magnetic loss tangent is the largest in this frequency range.

Calculations showed that the optimum layer thickness for the synthesis of absorbing components on the basis of $\mathrm{FeCoAl} / \mathrm{C}$ nanocomposites differs substantially for specimens synthesized at different temperatures (Fig. 6). For example, for nanocomposites synthesized at $700{ }^{\circ} \mathrm{C}$ the optimum thicknesses are 1.5 and $4.2 \mathrm{~mm}$. The reflection loss coefficient (RL) is as high as $-36 \mathrm{~dB}$ (absorption coefficient 0.984 ). For nanocomposites synthesized at 500 and $600{ }^{\circ} \mathrm{C}$ the optimum layer thicknesses are at higher frequencies compared with the range considered (3-13 GHz).

The calculation results suggest (Fig. 6) that the specimens synthesized at 500 and $600{ }^{\circ} \mathrm{C}$ have low efficiencies over the entire range of frequencies and thicknesses since their absorption coefficient is within $57 \%(\mathrm{RL} \geq 7.2 \mathrm{~dB})$. For $\mathrm{FeCoAl} / \mathrm{C}$ nanocomposite synthesized at $700{ }^{\circ} \mathrm{C}$ having the optimum thickness the maximum absorption is

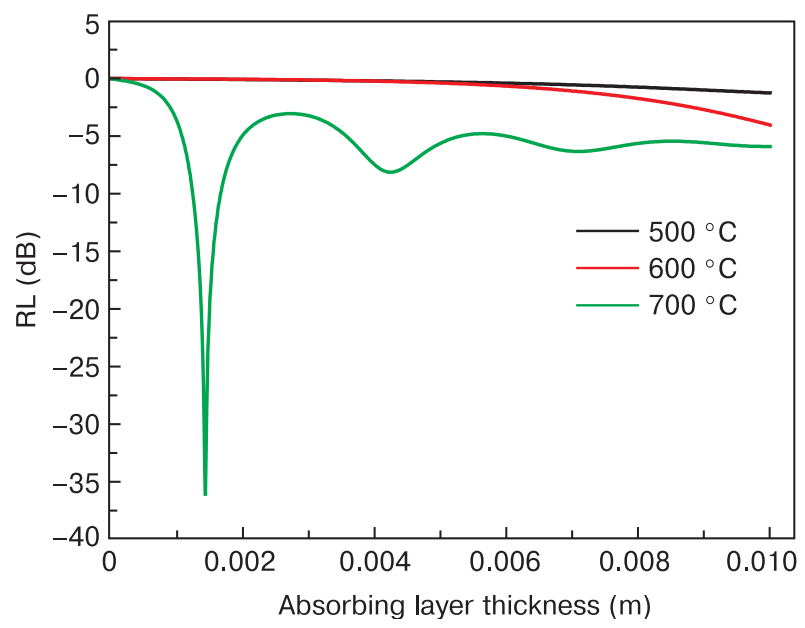

Figure 6. Optimization of absorbing layer thickness. 


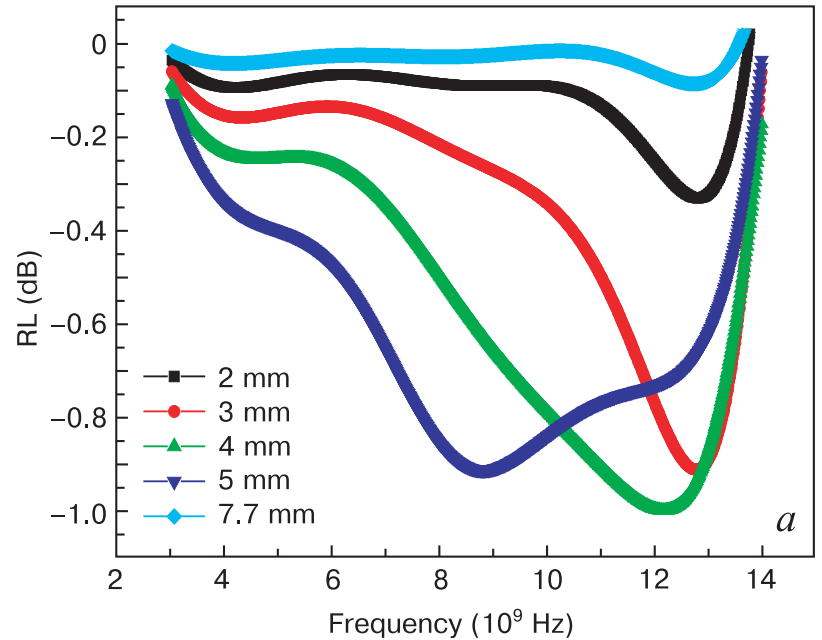

Figure 7. Frequency dependences of reflection coefficient of $\mathrm{FeCoAl} / \mathrm{C}$ nanocomposites synthesized at different temperatures $T_{\text {synth }},{ }^{\circ} \mathrm{C}:(a) 500,(b) 600$ and (c) 700 .

achieved at $13.8 \mathrm{GHz}$ for an absorbing layer thickness of $1.5 \mathrm{~mm}$ and with an increase in the nanocomposite layer thickness the minimum reflection (maximum absorption) shifts towards lower frequencies and reaches $-17 \mathrm{~dB}$ at a $7 \mathrm{~mm}$ thickness.

Calculated data for reflection loss taking into account nanocomposite position on metal are shown in Fig. 7.

We also studied the effect of metal ratio in the precursor on the electromagnetic and radio absorption properties of the $\mathrm{FeCoAl} / \mathrm{C}$ nanocomposites. The studies showed that the dielectric loss tangent and the dielectric permeability components decrease with an increase in the fraction of aluminum (Fig. $8 a$ and $c$ ) which seems to be caused by an increase in the overall electrical conductivity of the nanocomposite.

The magnetic loss is almost constant although the formation of larger cobalt based solid solution particles makes the spectrum more uniform in the $3-13 \mathrm{GHz}$ frequency range, growing from 0.03 to 0.1 rel.u.

Calculated data on the reflection loss taking into account nanocomposite position on the metal are shown in Fig. 9.

The minimum reflection $(\mathrm{RL}=-14.3 \mathrm{~dB})$ and the maximum absorption $(80.7 \%$ ) can be achieved at an absorbing layer thickness of $3 \mathrm{~mm}$ which is inferior to other
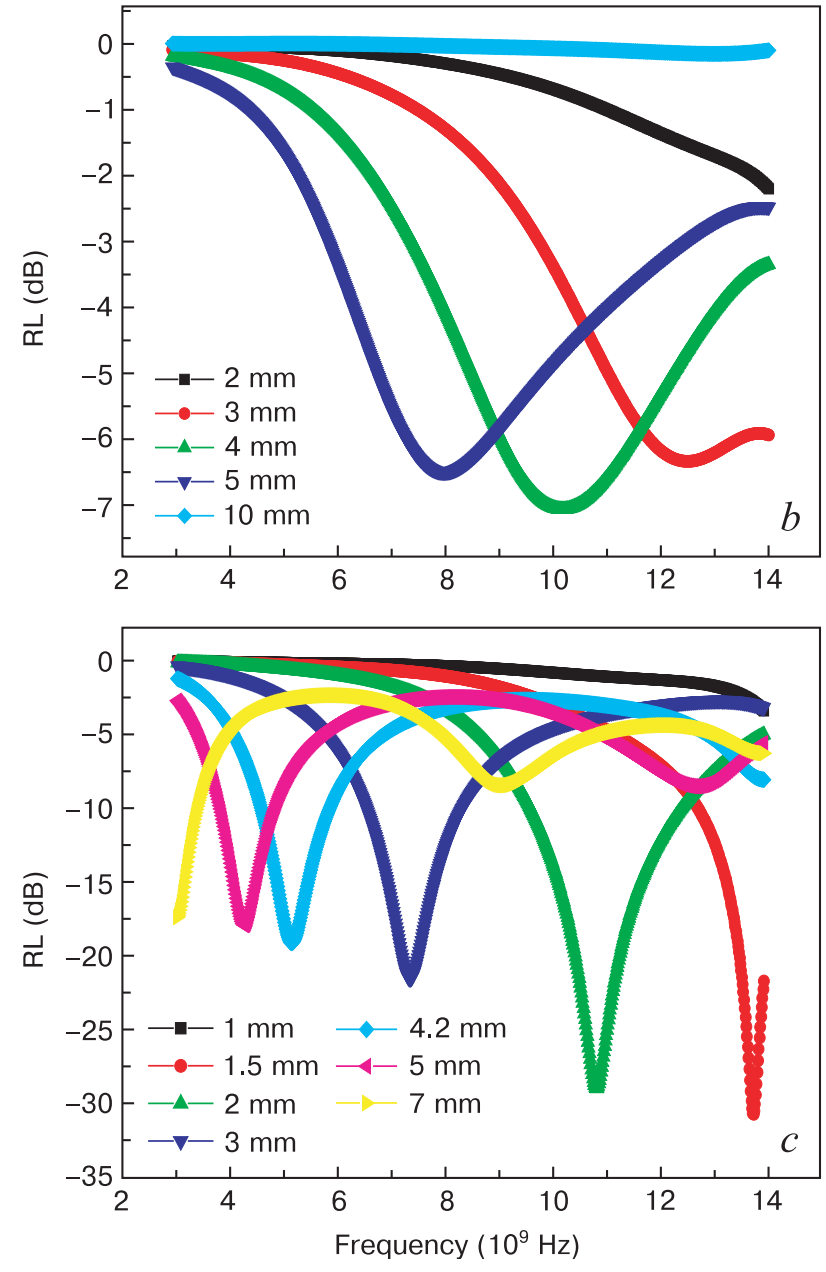

nanocomposites and to $\mathrm{FeCoAl} / \mathrm{C}$ nanocomposite with the $40: 40: 20$ metal content ratio.

Thus the most promising $\mathrm{FeCoAl} / \mathrm{C}$ nanocomposites are those synthesized at $T_{\text {synth }}=700{ }^{\circ} \mathrm{C}$ and having the metal content ratio $\mathrm{Fe}: \mathrm{Co}: \mathrm{Al}=40: 40: 20$.

\section{Conclusion}

The possibility of synthesizing nanocomposites containing nanoparticles of the FeCoAl ternary alloy (solid solution) using IR pyrolysis of metallic precursors was demonstrated. Nanoparticles of fcc $\mathrm{Co}$ and bcc FeCo based solid solutions form with an increase in the synthesis temperature leading to an increase in the size of the coherent scattering region for alloy nanoparticles from 5 to $19 \mathrm{~nm}$ due to agglomeration and coalescence of the metals in the course of reduction. An increase in the fraction of aluminum entails a decrease in the size of FeCoAl nanoparticles having a bcc lattice $(15 \mathrm{~nm})$ and an increase in the fraction of nanoparticles having an fcc lattice. An increase in the synthesis temperature and the fraction of aluminum in the nanocomposite lead to the formation of a more ordered nanocomposite carbon matrix which shows itself in a higher degree of crystallinity and a decrease in the amor- 

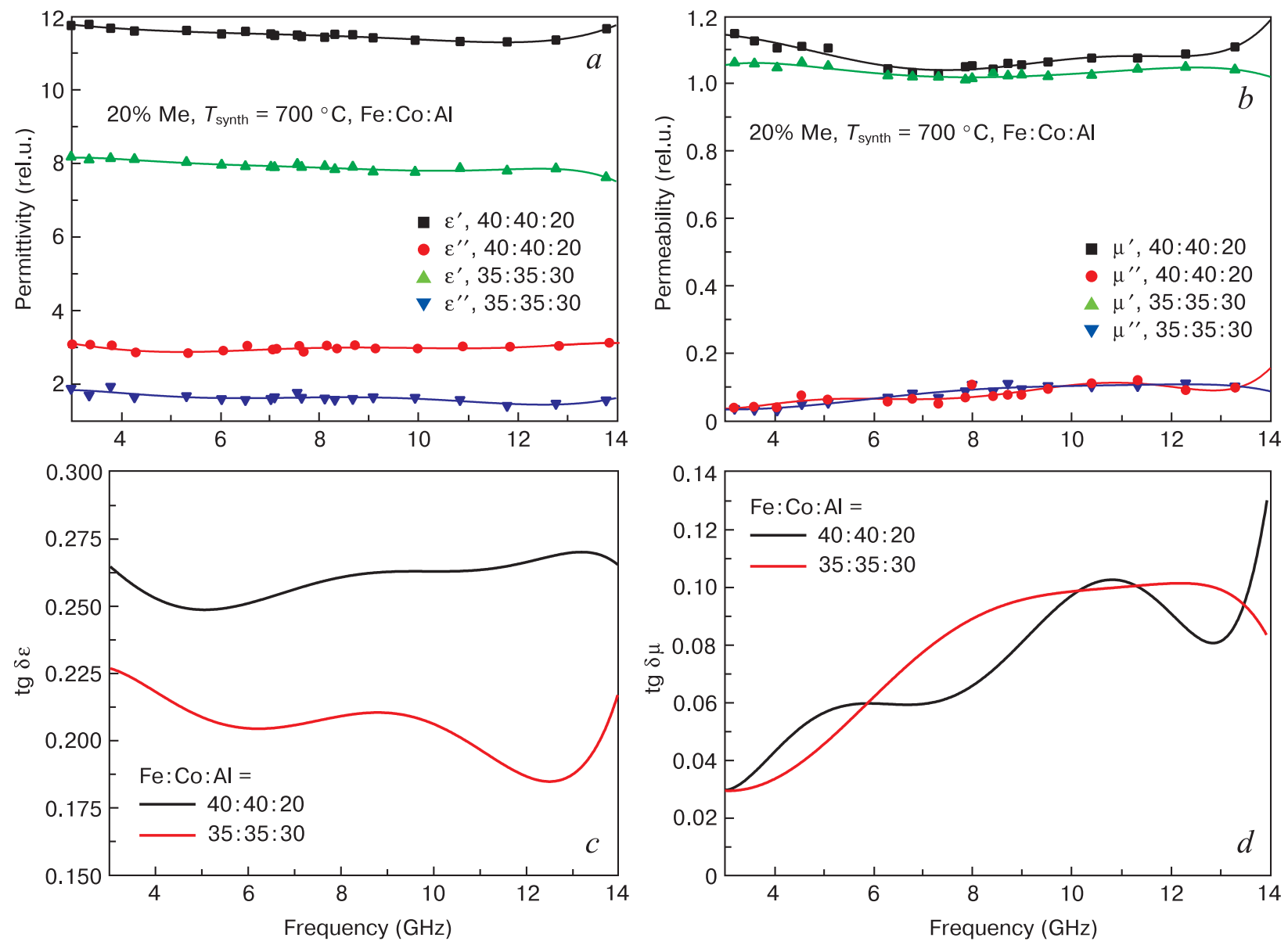

Figure 8. Frequency dependences of $(a)$ complex permittivity and $(b)$ permeability and tangents of $(c)$ dielectric and $(d)$ magnetic loss for different metal ratios in precursor.
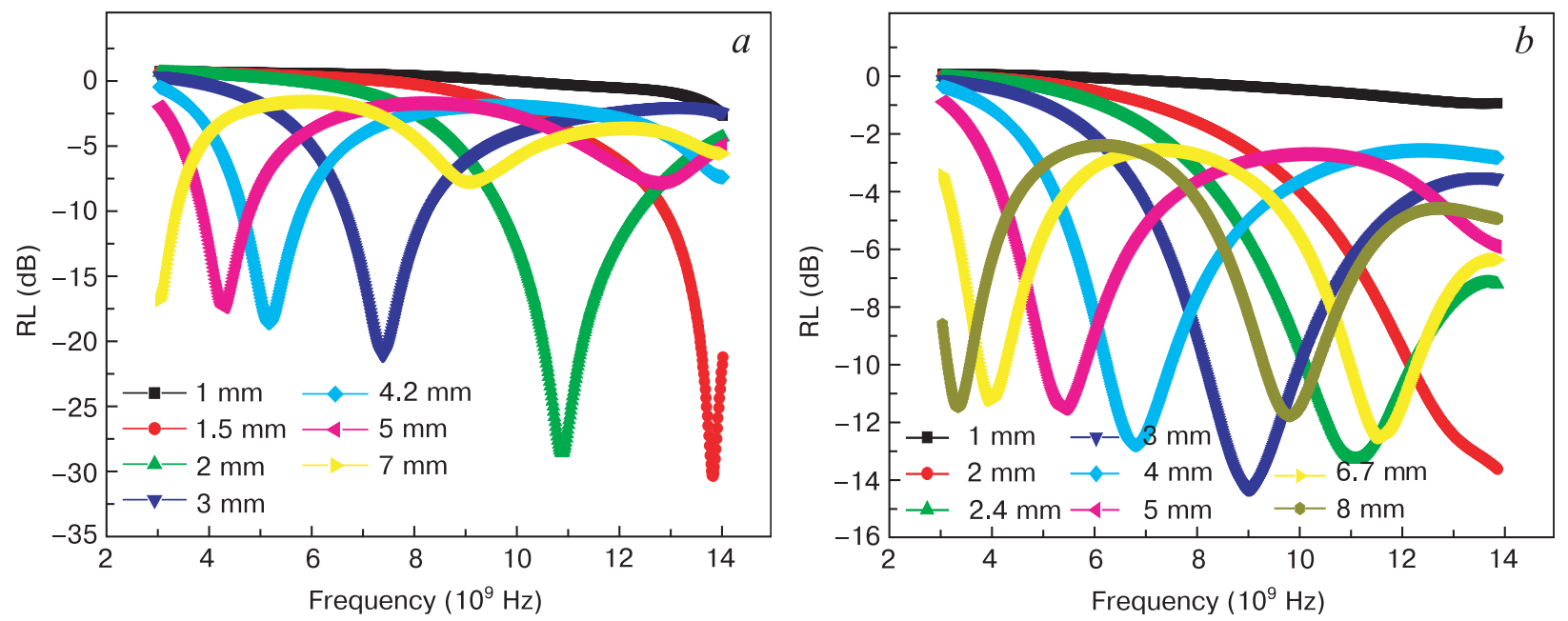

Figure 9. Frequency dependences of reflection coefficient of nanocomposites for different metal content ratios in precursor Fe : Co : Al: (a) $40: 40: 20 ;(b) 35: 35: 30$.

phousness degree. Matrix structurization leads to an increase in the dielectric loss due to the formation of crystalline inhomogeneities and a decrease in the amorphousness degree. In the meantime an increase in the size of nanoparticles entails an increase in the magnetic loss upon interaction with microwave radiation in the $3-13 \mathrm{GHz}$ range. Furthermore the interaction between the nanocomposite matrix and alloy nanoparticles increases the permittivity thus providing for a deeper penetration of electromagnetic waves into the material and more efficient energy dissipation. The most promising radio absorbing materials are $\mathrm{FeCoAl} / \mathrm{C}$ nanocomposites synthesized at $700{ }^{\circ} \mathrm{C}$. Their reflection loss is from -17 to $-31 \mathrm{~dB}$ which corresponds to a 86 to $97.2 \%$ absorption index. 


\section{References}

1. Gubin S.P., Spichkin Y.I., Yurkov G.Yu., Tishin A.M. Nanomaterial for high-density magnetic data storage. Russian J. Inorg. Chem., 2002; 47(1): S32-S67. http://www.amtc.ru/publications/ articles/5rus.pdf

2. Lu An-Hui, Salabas E.L., Schüth F. Magnetic nanoparticles: synthesis, protection, functionalization, and application. Angew. Chem. Int. Ed., 2007; 46(8): 1222-1244. https://doi.org/10.1002/ anie. 200602866

3. Xu Y.H., Bai J., Wang J.P. High-magnetic-moment multifunctional nanoparticles for nanomedicine applications. J. Magn. Magn. Mater, 2007; 311(1): 131-134. https://doi.org/10.1016/j. jmmm.2006.11.174

4. Khadzhiev S.N., Kulikova M.V., Ivantsov M.I., Zemtsov L.M, Karpacheva G.P., Muratov D.G., Bondarenko G.N., Oknina N.V. Fischer-Tropsch synthesis in the presence of nanosized iron-polymer catalysts in a fixed-bed reactor. Pet. Chem., 2016; 56(6): 522-528. https://doi.org/10.1134/S0965544116060049

5. Xu M.H., Zhong W., Qi X.S., Au C.T., Deng Y., Du Y.W. Highly stable $\mathrm{Fe}-\mathrm{Ni}$ alloy nanoparticles encapsulated in carbon nanotubes: Synthesis, structure and magnetic properties. J. Alloys Compd., 2010; 495(1): 200-204. https://doi.org/10.1016/j.jallcom.2010.01.121

6. Bahgat M., Paek M.-K., Pak J.-J. Comparative synthesize of nanocrystalline $\mathrm{Fe}-\mathrm{Ni}$ and $\mathrm{Fe}-\mathrm{Ni}-\mathrm{Co}$ alloys during hydrogen reduction of $\mathrm{Ni}_{x} \mathrm{CO}_{1-x} \mathrm{Fe}_{2} \mathrm{O}_{4}$. J. Alloys Compd., 2008; 466(1-2): 59-66. https:// doi.org/10.1016/j.jallcom.2008.01.147

7. Azizi A., Yoozbashizadeh H., Sadmezhaad S.K. Effect of hydrogen reduction on microstructure and magnetic properties of mechanochemically synthesized Fe-16.5Ni-16.5Co nano-powder. J. Magn. Magn. Mater., 2009; 321(18): 2729-2732. https://doi.org/10.1016/j. jmmm.2009.03.085

8. Li X., Takahashi S. Synthesis and magnetic properties of Fe-Co-Ni nanoparticles by hydrogen plasma-metal reaction. J. Magn. Magn. Mater, 2000; 214(3): 195-203. https://doi.org/10.1016/S03048853(00)00081-0

9. Dalavi S.B., Theerthagiri J., Raja M.M., Panda R.N. Synthesis, characterization and magnetic properties of nanocrystalline $\mathrm{Fe}_{x-}$ $\mathrm{Ni}_{80-x} \mathrm{Co}_{20}$ ternary alloys. J. Magn. Magn. Mater., 2013; 344: 30-34. https://doi.org/10.1016/j.jmmm.2013.05.026

10. Prasad N.Kr., Kumar V. Microstructure and magnetic properties of equiatomic FeNiCo alloy synthesized by mechanical alloying. $J$. Mater. Sci: Mater. Electron., 2015; 26(12): 10109-10118. https:// doi.org/10.1007/s10854-015-3695-7

11. Zehani K., Bez R., Boutahar A., Hlil E.K., Lassri H., Moscovici J., Mliki N., Bessais L. Structural, magnetic, and electronic properties of high moment FeCo nanoparticles. J. Alloys Compd., 2014; 591: 58-64. https://doi.org/10.1016/j.jallcom.2013.11.208

12. Nautiyal P., Seikh Md.M., Lebedev O.I., Kundu A.K. Sol-gel synthesis of $\mathrm{Fe}-\mathrm{Co}$ nanoparticles and magnetization study. J. Magn. Magn. Mater., 2015; 377: 402-405. https://doi.org/10.1016/j. jmmm.2014.10.157

13. Ang K.H., Alexandrou I., Mathur N.D., Amaratunga G.A.J., Haq S. The effect of carbon encapsulation on the magnetic properties of $\mathrm{Ni}$ nanoparticles produced by arc discharge in de-ionized water. Nanotechnology, 2004; 15(5): 520-524. https://doi.org/10.1088/09574484/15/5/020

14. Afghahi S.S.S., Shokuhfar A. Two step synthesis, electromagnetic and microwave absorbing properties of FeCo@C core-shell nanostructure. J. Magn. Magn. Mater, 2014; 370: 37-44. https://doi. org/10.1016/j.jmmm.2014.06.040
15. Ibrahim E.M.M., Hampel S., Wolter A.U.B., Kath M., El-Gendy A.A., Klingeler R., Täschner C., Khavrus V.O., Gemming T., Leonhardt A., Büchner B. Superparamagnetic FeCo and FeNi nanocomposites dispersed in submicrometer-sized C spheres. J. Phys. Chem. C, 2012; 116(42): 22509-22517. https://doi.org/10.1021/ jp304236x

16. Liu X.G., Ou Z.Q., Geng D.Y., Han Z., Jiang J.J., Liu W., Zhang Z.D. Influence of a graphite shell on the thermal and electromagnetic characteristics of FeNi nanoparticles. Carbon, 2010; 48(3): 891-897. https://doi.org/10.1016/j.carbon.2009.11.011

17. Liu X., Or S.W., Ho S.L., Cheung C.C., Leung C.M., Han Z., Geng D., Zhang Z. Full X-Ku band microwave absorption by $\mathrm{Fe}(\mathrm{Mn}) / \mathrm{Mn}_{7} \mathrm{C}_{3} / \mathrm{C}$ core/shell/shell structured nanocapsules. $J$. Alloys Compd., 2011; 509(37): 9071-9075. https://doi.org/10.1016/j. jallcom.2011.06.031

18. Liu Q., Cao B., Feng C., Zhang W., Zhu S., Zhang D. High permittivity and microwave absorption of porous graphitic carbons encapsulating Fe nanoparticles. Compos. Sci. Technol., 2012; 72(13): 1632-1636. https://doi.org/10.1016/j.compscitech.2012.06.022

19. Xie Zh., Geng D., Liu X., Ma S., Zhang Zh. Magnetic and microwave-absorption properties of graphite-coated $(\mathrm{Fe}, \mathrm{Ni})$ nanocapsules. J. Mater. Sci. Technol., 2011; 27(7): 607-614. https://doi. org/10.1016/S1005-0302(11)60115-1

20. Yang Y., Qia S., Wang J. Preparation and microwave absorbing properties of nickel-coated graphite nanosheet with pyrrole via in situ polymerization. J. Alloys Compd., 2012; 520: 114-121. https:// doi.org/10.1016/j.jallcom.2011.12.136

21. Zhao D.L., Zhang J.M., Li X., Shen Z.M. Electromagnetic and microwave absorbing properties of Co-filled carbon nanotubes. J. Alloys Compd., 2010; 505(2): 712-716. https://doi.org/10.1016/j. jallcom.2010.06.122

22. Zhao D.L., Li X., Shen Z.M. Preparation and electromagnetic and microwave absorbing properties of Fe-filled carbon nanotubes. J. Alloys Compd., 2009; 471(1-2): 457-460. https://doi. org/10.1016/j.jallcom.2008.03.127

23. Fan Y., Yang H., Liu X., Zhu H., Zou G. Preparation and study on radar absorbing materials of nickel-coated carbon fiber and flake graphite. J. Alloys Compd., 2008; 461(1-2): 490-494. https://doi. org/10.1016/j.jallcom.2007.07.034

24. Zhang T., Huang D., Yang Y., Kang F., Gu J. $\mathrm{Fe}_{3} \mathrm{O}_{4} /$ carbon composite nanofiber absorber with enhanced microwave absorption performance. Mater. Sci. Eng. B, 2013; 178(1): 1-9. https://doi. org/10.1016/j.mseb.2012.06.005

25. Lu B., Dong X.L., Huang H., Zhang X.F., Zh X.G., Lei J.P., Sun J.P. Microwave absorption properties of the core/shell-type iron and nickel nanoparticles. J. Magn. Magn. Mater, 2008; 320(6): 1106-1111. https://doi.org/10.1016/j.jmmm.2007.10.030

26. Wang B., Zhang J., Wang T., Qiao L., Li F. Synthesis and enhanced microwave absorption properties of $\mathrm{Ni} @ \mathrm{Ni}_{2} \mathrm{O}_{3}$ core-shell particles. J. Alloys Compd., 2013; 567: 21-25. https://doi.org/10.1016/j.jallcom.2013.03.028

27. Wang Z., Xiao P., He N. Synthesis and characteristics of carbon encapsulated magnetic nanoparticles produced by a hydrothermal reaction. Carbon, 2006; 44(15): 3277-32841. https://doi.org/10.1016/j. carbon.2006.06.026

28. Singh A., Lavigne P. Deposition of diamond-like carbon films by low energy ion beam and d.c. magnetron sputtering. Surf. Coat. Technol., 1991; 47(1-3): 188-200. https://doi.org/10.1016/02578972(91)90281-Z 
29. Dumitrache F., Morjan I., Fleaca C., Birjega R., Vasile E., Kuncser V., Alcxandrescu R. Parametric studies on iron-carbon composite nanoparticles synthesized by laser pyrolysis for increased passivation and high iron content. Appl. Surf. Sci., 2011; 257(12): 5265-5269. https://doi.org/10.1016/j.apsusc.2010.11.069

30. Yu F., Wang J.N., Sheng Z.M., Su L.F. Synthesis of carbon-encapsulated magnetic nanoparticles by spray pyrolysis of iron carbonyl and ethanol. Carbon, 2005; 43(14): 3018-3021. https://doi. org/10.1016/j.carbon.2005.06.008

31. Lin X.G., On Z.Q., Geng D.Y., Han Z., Jiang J.J., Lin W., Zhang Z.D. Influence of a graphite shell on the thermal and electromagnetic characteristics of FeNi nanoparticles. Carbon, 2010; 48(3): 891-897. https://doi.org/10.1016/j.carbon.2009.11.011

32. Pat. $2686223 \mathrm{Cl}$ (RU). Method of syntheses of nanocomposites Ag/C. L.V. Kozhitov, V.S. Sonkin, A.R. Muraleev, E.G. Sidin, D.D. Maganov, D.G. Muratov, E.V. Yakushko, A.V. Popkova, 2019. (In Russ.). https://patents.s3.yandex.net/RU2686223C1_20190424. pdf

33. Pat. 2593145 (RU). Method of producing $\mathrm{FeNi}_{3} / \mathrm{C}$ nanocomposite on industrial scale. L.V. Kozhitov, V.V. Kozlov, D.G. Muratov, V.G. Kostishin, E.V. Yakushko, G.E. Gelman, 2016. (In Russ.). https://patents.s3.yandex.net/RU2593145C1_20160727.pdf

34. Muratov D.G., Kozlov V.V., Krapukhin V.V., Kozhitov L.V., Karpacheva G.P., Zemtsov L.M. Study of electrical conductivity and semiconductor properties of a new carbon material based on IR-pyrolyzed polyacrylonitrile $\left(\left(\mathrm{C}_{3} \mathrm{H}_{3} \mathrm{~N}\right)_{n}\right)$. Izvestiya Vysshikh Uchebnykh Zavedenii. Materialy Elektronnoi Tekhniki = Materials of Electronics Engineering, 2007; (3): 26-30. (In Russ.)
35. Kozitov L.V., Kostikova A.V., Kozlov V.V., Bulatov M.F. The $\mathrm{FeNi}_{3} / \mathrm{C}$ nanocomposite formation from the composite of $\mathrm{Fe}$ and $\mathrm{Ni}$ salts and polyacrylonitrile under IR-heating. J. Nanoelectron. Optoelectron., 2012; (7): 419-422.

36. Zemtsov L.M. Karpacheva G.P., Efimov M.N., Muratov D.G., Bagdasarova K.A. Carbon nanostructures Based on IR-pyrolyzed polyacrylonitrile. Vysokomolekulyarnye soedineniya. Ser. A, 2006; 48(6): 977-982.

37. Karpacheva G.P., Bagdasarova K.A., Bondarenko G.N., Zemtsov L.M., Muratov D.G., Perov N.S. Co-carbon nanocomposites based on IR-pyrolyzed polyacrylonitrile. Polymer Sci. A, 2009; 51(11-12): 1297-1302. https://doi.org/10.1134/ S0965545X09110157

38. Dzidziguri L., Zemtsov L.M., Karpacheva G.P., Muratov D.G., Sidorova E.N. Preparation and structure of metal-carbon nanocomposites Cu-C. Nanotechnol. Russia, 2010; 5(9-10): 665-668. https:// doi.org/10.1134/S1995078010090119

39. Ferrari A.C., Robertson J. Interpretation of Raman spectra of disordered and amorphous carbon. Phys. Rev. B, 2000; 61(20): 1409514107. https://doi.org/10.1103/physrevb.61.14095

40. Tuinstra F., Koenig J.L. Raman spectrum of graphite. J. Chem. Phys., 1970; 53(3): 1126-1130. https://doi.org/10.1063/1.167410

41. Ferrari A.C. Raman spectroscopy of graphene and graphite: Disorder, electron-phonon coupling, doping and nonadiabatic effects. Solid State Commun., 2007; 143(1-2): 47-57. https://doi.org/10.1016/j. ssc.2007.03.052 